\title{
Chewable Capsule Dosage Form
}

National Cancer Institute

\section{Source}

National Cancer Institute. Chewable Capsule Dosage Form. NCI Thesaurus. Code C64876.

A capsule designed to be chewed to release the active and/or inert ingredient(s). 